\title{
CONTEMPORARY ASPECTS OF THE TRAINING IN THE PROFESSIONAL SECTOR OF HEALTHCARE
}

\author{
Hristina Milcheva \\ Medical College, Trakia University, Stara Zagora, Bulgaria
}

\begin{abstract}
The professions in the sector of healthcare have been undergoing an upward development during the last few decades. The preconditions for this are: harmonization of the training with the European standards and directives; the needs of the national and European health systems of qualified specialists; the constantly increasing deficit of health professionals; the demographic factor; the enhanced need of care, etc.

AIM: The aim of this research is to analyze some contemporary aspects, referring to the overall organization and implementation of the training process in the professional sector of healthcare within the university structure.

MATERIALS AND METHODS: The author has used an inquiry method, an interview, analysis of training records and statutory documents.

RESULTS AND DISCUSSION: On the basis of the research, conducted in the last years as well as the author's own observations and experience, some contemporary aspects of the training in the sector of healthcare have been analyzed with regards to: its organization and implementation within the university structure; the performed accreditations; the students' admission; possibilities for international exchange and self-realization.
\end{abstract}

Keywords: organization, needs, good practices, collaboration, self-realization

The professions in the sector of healthcare have been undergoing an upward development during the last few decades. The preconditions for this are: harmonization of the training with the European standards and directives; the needs of the national and European health systems of qualified specialists; the constantly increasing deficit of health professionals; the demographic factor; the enhanced need of care, etc.

The training of health professionals in contemporary conditions is carried out at the higher medical schools (HMS) - faculties and colleges.

Address for correspondence:

Hristina Milcheva

Medical College

Trakia University

9 Armeyska St

Stara Zagora

e-mail:milcheva@uni-sz.bg
The primary mission of HMS is to prepare highly qualified health professionals, possessing the necessary competence for work in all health areas.

\section{AIM}

The aim of this survey is to analyze some contemporary aspects, referring to the overall organization and implementation of the training process in the professional sector of healthcare within the university structure.

\section{MATERIALS AND METHODS}

The author has used an inquiry method, an interview, analysis of training records and statutory documents.

An analysis is done on some aspects of the training on the basis of conducted inquiries and interviews with students and university staff from the healthcare sector as well as with mentors from the 
clinical bases of Trakia University - Stara Zagora, for the period from 2008 until 2016.

\section{RESULTS AND DISCUSSION}

The contemporary aspects of the training in the healthcare sector at HMSs (Faculties of Medicine and medical colleges) are focused on: the student's admission, its organization and implementation within the university structure, the accreditation procedures, the material and technical base, the opportunities for international exchange and self-realization and the advance of the scientific work (see Fig. 1.).

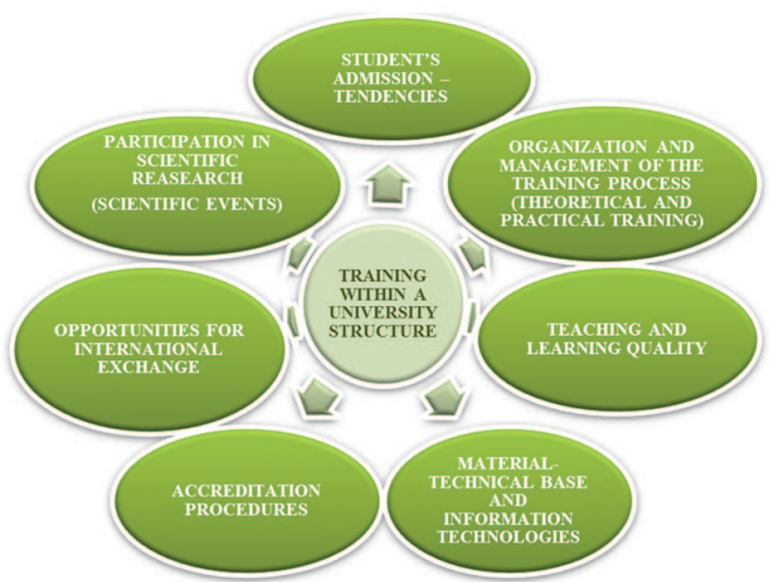

Fig. 1. Contemporary aspects of the training in the professional sector of healthcare

With regard to the student's admission, a diversification is established to attract applicants, including the overall organization and carrying out of the student admission exams and recognizing the final matriculation examination results from the secondary school for admission to the specialties in the healthcare sector.

A tendency is observed in the last years for maintaining an interest in healthcare professions (number of applicants), however, parallel to this - a decrease in the number of applicants as a whole, as a result of the decreased number of secondary-school graduates (6). The conducted investigations show that young people choose medical professions in order to find quicker and more efficient self-realization with regard to the serious deficit of personnel in these professions both in our country and in the other European countries as well.

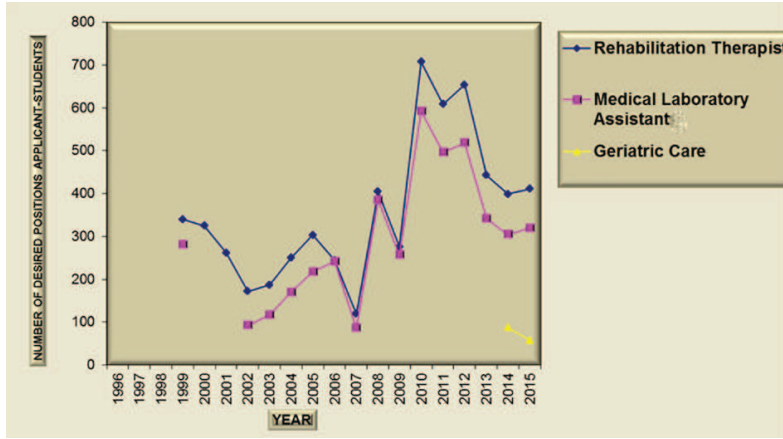

Fig. 2. A statistical extract of the students' admissions results from the Trakia University-Stara Zagora, for the

last years

With regard to the overall organization and implementation of the training process within the university structure, a success is observed for the programs with Bachelor's degree from the healthcare sector at the Faculties of Healthcare and Medicine, pursuant to the regulations $(1,2)$. The training of the programs at the HMSs in a university setting sets up new requirements with regards to its organization and management. In compliance with the mentioned regulations, the practical training is carried out and supervised by medical specialists with the following degrees: Nurse, Midwife, Rehabilitation Therapist, etc. and with Master's or Bachelor's degree in Healthcare Management. This requirement is valid both for the lecturers on the special academic subjects and the mentors - senior medical specialists at the clinical bases (4).

The course of the training process and the formation of professional competences in the contemporary conditions at the HMS require a high level of theoretical knowledge, practical skills, disposition and ability for team work; improvement of the communication skills; deliberate development of creative thinking; extending the forms of team work; improvement of the training methods with a focus on the interactive methods; increasing the share of independent work of the students in the development of a particular topic from the curriculum in the form of a course work or a project.

The theoretical training on the specified academic subjects is performed by qualified university staff from the respective scientific field. The Academic Staff Development Act, passed in 2011, opens up new opportunities for professional growth of the 
Hristina Milcheva

health professionals. The qualification in professional areas allows the academic staff to advance in their academic career as well as in the professional healthcare sector.

The role of the lecturer in charge of the special academic subjects is also changing - from a lecturer into a moderator, innovator and experimenter, permanently improving professional competences and qualifications. A contemporary aspect of the training of health professionals is the goal for the graduates to be very well prepared professionally, to possess skills for communication with the patients and their families. In order to achieve this goal, during their practical training in university conditions (specialized halls) and outside conditions (the clinical bases), the students practice their skills as well as different techniques for communication and training of the patients. An additional elective academic subject is "Psychosocial Communication in the Profession", which allows them to acquire additional information, communication and training techniques.

The content of the training of health professionals at the HMS has already acquired a scientific focus, namely - adopting a new philosophy and concept of the profession, based on the holistic approach to provision of healthcare and professional behavior for planning, organization, analysis, implementation and evaluation of the care. This is a competence which is acquired during the university education and affords the opportunity to develop creativity and a clinical approach when performing the main functions of the profession. As some other authors state (S. Dimitrova), “..... the university education of nurses affords an opportunity for a better professional training and extends the competence of the nurses, in conformity with the new philosophy of the profession" (4).

This, on the other side, requires a new approach to the organization of the training within the university structures, which is a challenge, especially in the conditions of reforms. The reforms in the area of healthcare directly affect the medical education. The most affected ones are the specialists from the regulated professions- physicians, nurses, midwifes and the rest of the health specialists. The adopted European Strategy for Smart, Sustainable and Inclusive Growth - 2020 offers a new vision for social market economy of Europe in the 21st century. One of the priorities of this strategy is related to education and employability of the young generation. In this aspect, the training of health professionals follows the priorities of the strategy and contributes to the solution of problems, related to the self-realization and mobility of the medical specialists in the European Union in order to overcome their deficit (4). The extension of the field of professional competences is a precondition for a wider self-realization in the area of healthcare.

The medical education is also in conformity with the directives of the European Union, especially the regulated professions with a view to the professional mobility within the European countries. The directives refer to the content of the training both in quantitative and qualitative aspect and their amendments require periodic amendments of our legislative framework for the training in health professions (4).

The latest amendments of the Regulations on acquiring higher education in the specialties from the professional healthcare sector for the education and qualification degree of Bachelor and Professional Bachelor at the Faculties of Medicine and the medical colleges are from 2008: Decree No. 238 of 26.09.2008, State Gazette No.87 and Decree No.257/ 01.11.2010, State Gazette No. 88 (1,2).

The education and qualification degrees of Bachelor for nurses, midwives, doctor's assistants, medical ergotherapists and Professional Bachelor for rehabilitation therapists, medical laboratory assistants, geriatric specialists, etc. guarantee more opportunities for self-realization both in the state medical facilities (MF) and in private structures, rehabilitation and spa centers and hospices. On the other hand, they are a basis to achieve a successful professional career.

Another important aspect and a condition for a qualitative training of the students is the material and technical base, which involves the condition of the training halls, auditoria, specialized rooms, laboratories and their software and technical equipment, the possibilities to use multimedia and internet as well as the rich library fund, with the available textbooks and journals, and the use of the electronic databases in the training (3). The advanced informa- 
tion technologies are a precondition for better awareness of the students, thus contributing to increased activity of the students and to turning them from an object of training into a subject of training. Increasing the opportunities to use information technologies in the training process requires the possession of skills for their use.

The accreditation procedures are an important and mandatory element of the contemporary training at the universities, whose results determine the state order for the number of students and the capacity of the separate specialties. After determining the professions in the sector of healthcare within the university structures, the accreditation and postaccreditation monitoring is a continual process. The results of the last accreditations of Trakia University show a very good level of conformity with the basic educational criteria for the regulated and non-regulated professions in the mentioned professional sector which achieved a very good rating $\left(3^{\text {rd }}\right.$ place $)$ for a second consecutive year (5).

Opportunities for International Exchange and Participation in Scientific Events

An important aspect of the training of health professionals is the opportunity of the academic staff and the students to participate in mobility under the Erasmus Program in addition to other ways. For Trakia University, the hosting and visiting mobility for academic staff and students from the healthcare sector is very well presented.

The participation in university projects is a major index for the advance of the scientific research work in the professional sector. The Student's Practices Project of the Ministry of Education and Science, funded by ESF, in which the students and employers had the opportunity to participate actively during the last two years, turned out to be very successful (7).

The participation of academic staff and students in scientific events is mandatory for their professional and academic advance. In the last years an upward trend has been observed in terms of participation in national and international scientific events in the field of healthcare.

Practical training is especially important for the professions from the healthcare sector, representing more than $50 \%$ of the overall training at the Uni- versity. It includes clinical practice, practice period, for some specialties also a summer internship and it is carried out at the medical facilities for inpatient and outpatient medical care, the specialized rehabilitation centers - under the supervision of lecturers in clinical practice and mentors according to schedules, prepared in advance and in compliance with the curriculum of clinical practice for each program.

The practice period is with the duration of one year for the programs Nurse and Midwife and for the rest - during the sixth semester of the third year. During this period the students perform practical work on particular patients, which includes activities, outlined in a Care Plan.

The afforded opportunity for free interpretation of the training content, the use of additional materials and textbooks and the Internet access contribute to a large extent to the diversification of the teaching and examination methods. The employment of modern didactic technologies enhances the academic motivation and responsibility of the students. The conducted inquiries and interviews with the students have shown that they are ready and willing to accept the tasks for independent work (preparation of a course work and a presentation) both in clinical practice and in the additional elective subjects as well as in some others. The presentation of a specific topic as a method finds an even wider application in the training of health professionals.

A special accent is placed on the promotion and prevention activity of the health professionals, which is an independent activity in the new qualification characteristics of the professions in the healthcare sector and in Regulation No.1 for the professional activities of health professionals (3).

The above presentation shows that in the contemporary conditions there are a number of challenges facing the people, engaged at different levels in the university structure. This is especially noticeable in the education management of the regulated professions. The appearance of new niches for self-realization requires a respective professional training of the graduates. The introduction of intermediate and integrated professional fields requires improvement and even development of new competences in areas, such as: health tourism, management, elderly care, 
etc. These are the main issues, which need adequate and timely solution.

\section{REFERENCES}

1. Regulation on the unified state requirements to acquire higher education in the specialties of the Healthcare professional sector for the educationalqualification degree "Bachelor", adopted with Decree No.257/01.11.2010. State Gazette; 88.

2. Regulation on the unified state requirements to acquire higher education in the specialties of the Healthcare professional sector for the educational-qualification degree "Professional Bachelor", adopted with Decree No.238/26.09.2008. State Gazette; 87.

3. Regulation 1 of 08.02 .2011 on the professional activities which the medical nurses, midwives, associated medical specialists and medical assistants can practice when employed or independently, issued by the Ministry of Health. State Gazette.2011;15.

4. Milcheva H. From tradition to innovation in the training of medical nurses and midwives. Gabrovo: EKS-PRES; 2012: 140.

5. Reports for program accreditation of the specialties in the regulated professions and non-regulated professions in the Healthcare professional sector, MC, Stara Zagora, 2015, 2016.

6. Statistics of the student's admission results of Trakia University - Stara Zagora, 2015.

7. www.europa.eu 